\title{
A prática de filosofia na escola como oportunidade de redefinição mútua de crianças $e$ adultos
}

Lúcia Helena Cavasin Zabotto Pulino1

[1]

A introdução da filosofia como disciplina em escolas de crianças tem se mostrado um campo fértil de questões que exigem uma reflexão cuidadosa $e$ constante por parte de educadores.

A primeira questão que surgiu foi, naturalmente, sobre a possibilidade de as crianças se envolverem em atividades de reflexão e prática filosóficas.

Sobre isso, Matthew Lipman2 [2] , o educador pioneiro em matéria de Filosofia para Crianças, escreveu uma exaustiva obra, em colaboração com outros estudiosos, em que fundamenta teoricamente a adequação da introdução de Filosofia na educação escolar de crianças. Essas, de acordo com ele, já são curiosas, e têm uma inclinação natural para perguntar e discutir. Dentre suas obras, destacam-se, inclusive, as chamadas novelas, ou romances, filosóficos, e guias para o professor, escritos com a finalidade de servirem de material a ser utilizado na aula de Filosofia, que ele sugere que se dê em uma comunidade de investigação, pois acredita ser esta a prática que permite que se desenvolva a melhor pedagogia para se apresentar a filosofia às crianças.

1 [1] Psicóloga (USP), professora assistente do Departamento de Psicologia Escolar e do Desenvolvimento - PED, do Instituto de Psicologia, da Universidade de Brasília (UnB). Mestre em Lógica e Filosofia da Ciência (UNICAMP) e Doutoranda em Filosofia (UNICAMP). Participou do Projeto de Extensão "Filosofia na Escola" da UnB.

2 [2] Fundador do Instituto para o Avanço de Filosofia para Crianças (IAPC), da Universidade Estadual de Montclair, Estados Unidos. 
O empenho em refletir, ler e discutir sobre essa primeira questão motivou educadores, psicólogos e filósofos no mundo todo, que se envolveram em programas de introdução de filosofia em escolas, seja como seguidores do método proposto por Lipman, ou desenvolvendo novas formas de compreender e praticar a filosofia nas escolas.

Com a experiência pioneira, a de seus seguidores $e$ as inovações que surgiram em programas teórico-práticos voltados para a introdução da filosofia para crianças, novas questões foram se delineando, a partir da aceitação da possibilidade de crianças filosofarem e essas questões são vetores que orientam o trabalho prático e a pesquisa de estudiosos da área de Filosofia com Crianças.

Assumir que a criança pode filosofar em sala de aula e desenvolver programas para viabilizar a introdução dessa disciplina nas escolas significa, mais do que assumir idéias e práticas, ter que fazer escolhas não só teóricas - como definir criança, filosofia e educação - mas também práticas - as estratégias pedagógicas - até porque umas e outras se interrelacionam.

Em nossa experiência no Programa Filosofia na Escola (PFE)3 [3] , temos nos orientado por algumas questões: Por que e para que introduzir-se Filosofia no currículo de escolas de crianças? Que filosofia é praticada nas escolas com crianças? Como preparar professores para essa nova disciplina?

Assim, a formação de professores, de estudantes universitários, estagiários e monitores, vem se desenvolvendo há 6 anos e, ao longo desse período de tempo, a construção de nossas idéias e práticas tem sido constante, envolvendo todas as pessoas comprometidas, já que não assumimos um método e idéias já prontas, mas elaboramos e re-elaboramos coletivamente nossas formas de trabalho $e$ estudo.

3 [3] Programa Filosofia na Escola (aqui designado como PFE), é um programa de extensão da Universidade de Brasília, que introduziu a disciplina Filosofia com crianças em algumas escolas públicas do DF, desde 1998 e promove a formação dos professores dessas escolas para trabalharem a nova disciplina. 
Um passeio por algumas publicações de participantes do PFE, especialmente as contidas em alguns livros da coleção Filosofia na Escola, da Editora Vozes4 [4] nos permite fazer um resgate de alguns pontos teórico-práticos que mereceram registro e reflexão de nossa parte, membros do Programa.

Esses pontos são calcados nas três questões mencionadas acima: sobre a concepção de filosofia que assumimos no PFE, sobre a justificativa e a finalidade da introdução da filosofia em escolas de crianças, e sobre as estratégias de formação de professores para essa nova disciplina.

Sobre a concepção de filosofia do PFE, o texto de Kohan5 [5], no Volume V, da Coleção Filosofia na Escola, de 2000, Filosofia na Escola Pública, entitulado "Fundamentos à prática da filosofia na escola pública" discute os elementos teórico-práticos que sustentam o trabalho nas escolas.

Vamos abordar as três questões a partir da reflexão sobre a infância que vem sendo mantida em nossa agenda de discussões.

A infância

A reflexão sobre a infância, que alicerça nossa prática-teórica de Filosofia com Crianças, critica a relação que os adultos temos tido com as crianças, classificando-as, reduzindo-as a projetos de adultos, que devem ser educadas para conseguirem se igualar a nós ou a um ideal de adulto socialmente esperado; protegendo-as com um estatuto, mas, ao mesmo tempo, reservando para elas uma vida espelhada da nossa, moldando-as aos nossos valores de exclusão e

4 [4] A coleção Filosofia na Escola consiste em 6 volumes.

5 [5] Kohan, Walter, "Fundamentos à prática da filosofia na escola pública" IN Filosofia na EscolaPública, coleção Filosofia na Escola, Vol. V Petrópolis, RJ: Vozes ed., 2000. pp. 21-73. 
exploração do outro, de que elas próprias são vítimas. Temos dificuldade, como educadores, de ver cada criança como uma pessoa na infância da vida, num mundo radicalmente diferente do nosso, que nos inquieta, porque por mais que a enquadremos em nossas teorias pré-fabricadas, cada uma é original e criativa e desafia nossas maneiras de pensar.

A educação historicamente tem tentado dissolver a infância, substituí-la por regras e procedimentos que dirigem e moldam o pensamento, as ações e a própria percepção das crianças. Pensa-se que a infância precisa desaparecer para surgir a condição adulta socializada.

No PFE, ressalta Kohan, "procuramos repeitar essa diferença, aceitar o enigma da infância. Não queremos conhecer as crianças, não queremos saber nada mais sobre a infância. Sabemos tudo o que precisamos saber: não sabemos nada dela. Queremos fazer filosofia com elas, ouvir sua forma de fazer filosofia, o que elas têm para dizer. Aprender com elas, delas. Queremos também deixá-las ser crianças, o que a escola tanto tenta impedir. Para isso, para poder ser aquilo que se quer ser, quem sabe a filosofia possa chegar a ser um bom caminho; porque para ser o que se quer ser, antes é preciso perguntar-se por aquilo que se é, como alguém torna-se o que é. Talvez, com o auxilio da filosofia as crianças possam questionar, saber recusar e transformar aquilo que estão sendo...posam voltar a ser crianças." (Kohan, 2000: p.67)

A argumentação apresentada acima torna clara nossa opção por fazer Filosofia com Crianças e não Filosofia para Crianças.

Nossa opção pode soar como ingênua, na medida em que supõe que se possa, como adultos, educadores inseridos numa estrutura escolar, escapar às múltiplas determinações ideológicas e teórico-práticas estabelecidas, "deixando" a criança ser criança, viver na infância. 
Sobre esse ponto, em "Acolher a criança, educar a criança" (Pulino, 2001)6 [6] , considero essas duas maneiras de lidar com a criança: 1) tentando enquadrála em nosso mundo e tirá-la da infância, ou 2) reconhecendo na criança um outro, o diferente, o novo, com que podemos nos relacionar, se não dissolvermos sua infância.

Sobre a primeira forma de se receber a criança. apresento uma compreensão do encontro criança-adulto, na escola, tomando como paradigma o encontro pais-bebê, desde o período de gestação, o nascimento de uma criança, $e$ os primeiros meses de relação pais-crianças. Aí, considero a concepção e a espera, a gestação, da criança, como calcada, num primeiro momento, numa promessa social, caracterizada pelo lugar que uma determinada cultura e sociedade reservam para a infância: como se constitui a família, quais as condições ótimas para se ter um filho, que responsabilidades isso envolve, qual o número médio de filhos naquela sociedade, como se valorizam os sexos dos filhos, como se altera a vida familiar com a chegada de uma criança, qual o sentido, enfim, de se ter um filho são valores e informações presentes numa sociedade.

Além dessa promessa social, que começa a forjar, já, a identidade de uma criança que pode ainda nem ter sido concebida, pela forma com a infância é concebida e tratada socialmente, os pais tecem, consciente e inconscientemente, durante a gravidez, uma matriz psicológica de formação da identidade da criança esperada - a matriz de identidade7 [7] , que, tal como a placenta fisológica, constitui-se no chão simbólico em que se enraíza o desejo e as expectativas dos pais. Essa matriz se insere na promessa maior, mas traz elementos originais, da história de vida de cada um dos pais e de sua vida conjugal, além das condições objetivas que se colocam para eles. Mas, e especialmente, é carregada de elementos inconscientes, de fantasias e das vicissitudes de cada um dos pais.

6 [6] Pulino, Lúcia. "Acolher a criança, educar a criança” IN Em Aberto, no. 73, vol 18. Brasília: julho de 2001. pp. 29-40.

7 [7] Este conceito é de Moreno, J. L. , apresentado em Psicodrama. São Paulo: Cultrix, 1975. 
No artigo mencionado, especifico: "A matriz de identidade se tece com fios da experiência de gestação dos pais, na tela da promessa social maior. Este é o "lugar" existencial da criança que está se formando, sua identidade sociopsíquica. Ao nascer, então, a criança já tem uma existência prévia, não encontra um espaço vazio a ser preenchido por ela. Ela entra num mundo povoado de imagens inspiradas na possibilidade de sua existência. E, a partir do momento de seu nascimento, inicia-se um processo de diálogo entre essas imagens e a do bebê que surge efetivamente." (Pulino, 2001, p. 32)

Usei, no artigo em questão, a história Peter Pan para ilustrar a forma como, pela matriz de identidade, os pais projetam a maneira de ser de um filho.

- Que idade você tem, Peter Pan?

- Não sei. Só sei que sou bastante criança. Fugi de casa no mesmo dia em que nasci.

- No mesmo dia em que nasceu? Que idéia! E por que, meu caro?

- Porque ouvi uma conversa entre meu pai e minha mãe sobre o que eu havia de ser quando crescesse. Ora, eu não queria crescer. Não queria, não quero nunca virar homem grande, de bigodeira na cara feito taturana. Muito melhor ficar sempre menino, não acha? Por isso fugi, $e$ fui viver com as fadas." (Barrie, 1987)8 [8]

O bebê, então, é a síntese dessas múltiplas determinações, dessas influências,desses desejos, que o transformariam num homem grande, com bigodeira na cara, mas também, e, especialmente, se autodetermina, que é o que está expresso na figura fugir, ficar sempre menino, ir viver com as fadas.

8 [8] Barrie, J. M. Peter Pan. Traduzido e recontado por Monteiro Lobato. IN Lobato, M. Emília e Peter Pan. S.P: Círculo do Livro, 1987. 
Tratando da segunda maneira de se receber a criança, considero que, a despeito desses mecanismos de construção de uma identidade prévia, o nascimento se constitui numa experiência inusitada, que nos traz uma novidade radical.

"A criança nasce. Nasce, irrompe. Rasga o limite que o corpo da mãe lhe impunha... O bebê surpreende. Como se não o esperassem, ..."saltando para dentro da vida" (ver citação abaixo).(Pulino, 2001, p.34)

No referido texto, usei trecho de Morte e Vida Severina9 [9], que relata o nascimento de uma criança, como um acontecimento completamente novo.

- Compadre José, compadre,

que na relva estais deitado:

conversais e não sabeis

que vosso filho é chegado?

Estais aí conversando

Em vossa prosa entretida:

Não sabeis que vosso filho saltou pra dentro da vida?

Saltou pra dentro da vida

Ao dar seu primeiro grito:

(...)

- Belo porque é uma porta

abrindo-se em mais saídas.

9 [9] Melo Neto, J. C. Morte e Vida Severina, IN Obras Completas. R.J.:Aguilar, 1994. p. 95 . 
- Belo como a última onda que o fim do mar sempre adia.

- Belo porque tem do novo

a surpresa e a alegria.

- Belo como a coisa nova

na prateleira até então vazia

- Como qualquer coisa nova

inaugurando o seu dia.

- Ou como o caderno novo quando a gente o principia.

- E belo porque com o novo

todo o velho contagia.

A poesia de João Cabral nos traz um desenho da infância como novidade, que nos contagia.

Sobre a questão do nascimento, nossa reflexão se sustenta em Jorge Larrosa (2000,p.187)10 [10] : "quando uma criança nasce, um outro aparece entre nós. E é um outro porque é sempre algo diferente da materialização, da satisfação de uma necessidade, do cumprimento de um desejo... é algo absolutamente novo, que dissolve a solidez do nosso mundo e que suspende a certeza que nós temos de nós próprios. Não é o começo de um processo mais ou menos antecipável, mas uma origem absoluta, um verdadeiro início."

Esse outro, essa novidade que a criança é ao nascer, é o sentido mesmo da infância, do novo, do que nos encanta e amedronta porque não conseguimos 10 [10] Larrosa, Jorge, Pedagogia Profana BH: Autêntica ed., 2000. 
dominar ou compreender totalmente. É essa a infância que, como vimos com Kohan acima, ignoramos por não sabermos o que fazer com ela, já que escapa às nossas teorias e enquadramentos.

Transpondo essa reflexão para o contexto escolar, por esse mesmo processo que se dá em relação à recepção das crianças que nascem, os educadores recebemos as crianças na escola, esperando já por crianças pré-determinadas, vivendo determinadas fases, pensando, sentindo e agindo de uma determinada maneira, ditada pelas teorias científicas e pela nossa experiência com outras crianças no passado e pelo ideal social de criança. Por outro lado, quando nos abrimos à experiência do encontro com um outro, somos surpreendidos pela originalidade e capacidade criativa de cada criança.

É comum não recebermos a própria criança, em sua concretude, quando a encontramos numa escola, mas já a enquadrarmos em parâmetros pré-definidos em nossa maneira de ver e falar. É uma forma de defendermos nossas convicções e mantermos nosso poder como educadores.

Alice no País das Maravilhas11 [11] foi a história infantil que usei para ilustrar esse ponto.

- Com quem você está falando, afinal? Perguntou o Rei, aproximando-se de Alice e olhando a cabeça do Gato, com grande curiosidade.

- Com um de meus amigos, o Gato Caçoador - disse Alice. - Permita que o apresente a Vossa Majestade.

- Não gosto da fisionomia dele. - disse o Rei. - Mas permito que me beije a mão, se isso lhe agradar.

11 [11] Carroll, Lewis. Alice no País das Maravilhas. Trad. Fernanda L. de Almeida. SP: ática ed., 1986. 
- Não faço a menor questão, respondeu o Gato.

- Não seja impertinente - disse o Rei - e não me olhe assim.

Dizendo isso escondeu-se atrás de Alice.

- Um gato tem o direito de olhar de frente um rei - disse Alice. - Li isso num livro, não me lembro qual.

- Seja como for, ele tem que ser tirado daí - disse o Rei, num tom decidido. E chamou a Rainha, que ia passando:- Minha querida, desejo que você faça esse Gato sumir daí.

A Rainha só tinha uma solução para todos os problemas, grandes ou pequenos:

- Cortem-lhe a cabeça! - gritou, sem mesmo olhar, para ver do que se tratava.

(Carroll, 1986, p. 86)

Alice é a criança, que traz o novo, a crítica, a reflexão, e a Rainha, o adulto, o dado, o mesmo, o sempre igual.

É certo que não seria possível encontrarmo-nos com a criança em si, pura de influências e determinações, no sentido da infância como novidade radical.

Mas também é certo que nossa consciência sobre a relatividade de nossas concepções e valores pode possibilitar que encontremos formas de permitirmos que a infância irrompa sem que a impeçamos, nem que seja por lampejos que nos surpreendam, entrando pelas brechas abertas por nós.

Trata-se, então, de abrirmos brechas, ou de não fecharmos nosso mundo a novas percepções, nossa linguagem a novas palavras, nossas atividades a novas ações. Trata-se, enfim, de saber receber o outro, o diferente de nós, e de dialogar com ele. 
As brechas podem ser abertas por pesquisas teóricas que nos levem a pensamentos diferentes dos nossos, por metodologias que envolvam materiais diversos, procedimentos novos e, especialmente, práticas que não se fechem em ações individuais.

É nesse sentido, certamente, que Kohan diz esperar que a Filosofia nas escolas abra caminho para a a infância entrar e as crianças serem como são e se transformarem no que querem ser.

Isso não significa que os participantes do PFE tenhamos nos vacinado contra as idéias e valores defendidos pelos métodos de socialização usados nas escolas. Só quer dizer que temos consciência de que é importante deixarmos brechas abertas em nossa prática-teórica, para que o novo nos atinja.

A prática de filosofia nas escolas, no trabalho do PFE, é uma prática-teórica coletiva, que leva em consideração cada criança em sua maneira de ser, desenvolve técnicas pedagógicas que convidam os alunos a participarem do encontro, efetivamente, que reservam um lugar a ser preenchido por eles: o lugar do outro, que assegura a necessidade do diálogo. Por isso, tantas vezes podemos reconhecer (especialmente no Volume V, da coleção Filosofia na Escola), em depoimentos de professores e monitores do PFE envolvidos com a prática nas escolas, que todo esforço é empenhado em valorizar os alunos, ouví-los durante todo o processo, da preparação, à realização e avaliação dos encontros.

A própria idéia de se introduzir a Filosofia no currículo de escolas de crianças já supõe que elas sejam vistas como capazes de pensar, de expressar suas idéias, de fazer críticas a alguns pensamentos e propor outros. O trabalho do PFE já é uma forma de abrir brechas para a entrada do novo, do diferente, do inesperado, em que pode consistir a participação das crianças na comunidade de investigação. 
No artigo "A brincadeira, o jogo, a criação: crianças e adultos filosofam" 12 [12] , (Pulino, 2002) apontei para o significado da brincadeira como uma atividade típica da criança e que, como tal, consiste em um aspecto da infância, do seu mundo original e diferente, que as instituições organizam, com finalidades educacionais.

Saliento, aí, que a Psicologia do Desenvolvimento tem estudado a brincadeira com o objetivo de explicar esse comportamento da criança $e$ compreender seu papel na formação da identidade infantil e nos processos de socialização de que ela participa. Considera que a criança, no jogo simbólico, ou na brincadeira de faz-de-conta, a criança assimila a realidade não imitando-a, mas apreendendo-a de forma original, imaginativa, e, dessa forma, capta o significado social das ações humanas, dando-lhes, já, um sentido pessoal. Constrói, a um só tempo, a realidade e sua identidade, enquanto brinca.

Da mesma forma que o jogo de faz-de-conta, os jogos de regra também cumprem esta tarefa dupla, na medida em que as ações ocorrem num espaço existencial distinto do social e ganham sentido na imaginação, embora forgem situações que dizem respeito às relações humanas reais.

Pois bem: retomando nossa reflexão sobre a prática de filosofia com crianças, poderíamos dizer que a brincadeira $e$ os jogos abrem espaços a serem preenchidos com ações que não se sabe exatamente como vão se desenrolar. E, como tal, podem dar uma contribuição importante ao exercício da filosofia, que pretende se desenvolver nesse padrão de abrir brechas para a acolhida da infância, do novo, da criação.

Sugeri, no citado artigo, que se deixasse de olhar a criança a partir da perspectiva de seu enquadramento no mundo adulto e se tentasse olhar o adulto a

12 [12] Pulino, Lúcia, "A brincadeira, o jogo, a criação: crianças e adultos filosofam", IN Ensino de Filosofia: perspectivas. Kohan, W, org., BH: Autêntica ed., 2002, pp. 213-231. 
partir da perspectiva da infância, como pessoa capaz de brincar, de criar - como pessoa que se abre à experiência da infância, do encontro com o novo.

$\mathrm{O}$ adulto, visto dessa perspectiva, pode compreender que a experiência de fazer filosofia com crianças é uma prática que se alimenta da novidade que a criança traz e para a qual ele abre espaço, despertando a ele mesmo para o jogo de perguntar, criticar, criar.

Parece-me que a primeira questão que levantamos começa a ser tratada aqui.

"Por que e para que se fazer Filosofia com Crianças?"

Contra a expectativa de educadores que pensam na educação como formação, como adaptação à sociedade, ou como forma de levar a um estado político-social pré-determinado, a filosofia com crianças, na perspectiva do PFE, pretende abrir espaço ao novo, ouvir a voz do outro, dialogar com ele e não lhe impor e uma maneira de ver e lidar com o mundo. Certamente, nesse diálogo vamos introduzir nossas próprias convicções, mas sempre tendo como principal objetivo abrir brechas e não fechar, concluir idéias.

A forma por excelência de se abrirem brechas é a pergunta. É a pergunta que deve orientar o trabalho teórico-prático da Filosofia com Crianças; a pergunta filosófica, que não peça uma resposta definitiva, mas que abra caminhos para a discussão, a busca de argumentação, que faça um apelo ao outro.

Conforme Kohan13 [13] , (Kohan, 2000, pp. 28-29): "As perguntas da filosofia abrem os diversos sentidos da crítica. Elas são perguntas que permitem reconhecer limites, explorar obviedades, por em questão valores... que mostram os

13 [13] Kohan, Walter, 2000, op. cit., pp. 28-29. 
limites dos outros saberes e das formas de vida em sociedade, que questionam as familiaridades (Alves, 1995, pp. 99-100), mordendo a realidade (Japiassu, 1997, p.103), que não deixam que o pensamento se interrompa em nenhuma parte (Horkheimer, 1940, p. 279); finalmente, as perguntas em filosofia são phármakon, porque procuram dissolver crenças e superstições (Matos,1997,162); sendo phármakon, elas são também terapêuticas porque instauram a autarquia de quem as pergunta; elas são antídotos contra os dogmas que se pretende impor como verdades (Savater, 1994, p. 1)".

Especificando mais ainda, "As perguntas da filosofia não são colocadas para serem respondidas, no sentido de serem resolvidas, mas para serem pensadas; e o pensamento não tem pontos de clausura. Ele sempre pode avançar mais um pouco." (Kohan, 2000, p.30)

O adulto, tanto quanto a criança, pode experienciar a condição da infância, de se surpreender com o novo, de olhar o mundo como se fosse pela primeira vez. E é isso que o leva a filosofar, a ter curiosidade, a questionar, a fazer, cada um, sua própria pergunta, dando sentido ao mundo, ao outro e a si.

A Filosofia com Crianças tem, assim, como objetivo, promover o encontro de vozes diversas, de pessoas diferentes que, com sua experiência de investigação, não buscam responder definitivamente a desafios teóricos e práticos, mas exercitar-se em olhar a realidade e atuar nela de maneira crítica e criativa. Em última instância, o que se busca, é manter sempre aberto um espaço para o novo.

Que filosofia se faz no PFE?

A filosofia é concebida como "busca, investigação coletiva, enquanto um perguntar aberto ao não pensado, àquelas peguntas que o sujeito mesmo quer fazer e não às boas perguntas, ou àquelas que já foram respondidas, é um filosofar crítico, contando com a contingência das idéias e da própria crítica; é fazer filosofia 
como uma experiência incerta, correndo riscos, "tirando o chão" seguro do que foi pensado no passado e tendo a história como interlocutor; é o filosofar como forma de resistência de um pensamento autônomo às formas padronizadas de pensamento globalizado; é o filosofar na busca de formas criativas de falar o mundo, de se relacionar esteticamente com a vida; é o filosofar enquanto possibilidade de participação política, de repensar as formas de dominação social e de escolher novos padrões de relacionamento e organização coletiva; é o fazer filosofia, de repensar as formas de dominação social e de escolher novos padrões de relacionamento e orgaização coletiva; é o fazer filosofia amando o saber e respeitando as pessoas com quem se compartilha esta prática." (Pulino, 2002, pp. 224-225)

A Filosofia assim concebida é bastante diferente das outras disciplinas ministradas na escola, já que, na contramão da proposta de consolidar conceitos, práticas e valores, característica do ensino que se oferece a crianças, ela abre novas possibilidades para o pensamento, questiona o dado e desestabiliza o aceito.

Assim, as mudanças que se efetuam na forma como as crianças se colocam frente a desafios não são apenas da ordem do discurso, mas de sua participação como membros da comunidade escolar. Nos relatos do Volume V, da coleção Filosofia na Escola, podemos reconhecer atitudes e falas das crianças que questionam a postura dos adultos da escola, como no comentário sobre a experiência de uma professora, citada por Merçon: "A profa. Cláudia relata que no começo de outubro de 1999 algumas idéias haviam surgido para a celebração do Dia das Crianças. Ela, no entanto, resolveu sozinha que as crianças iriam a uma lanchonete. Ao contar sua decisão para a turma, diz ter sido questionada de diversas maneiras. As crianças perguntavam porque havia tomado tal decisão sem consultá-las, quais seriam as consequências, se poderiam além de ir à lanchonete e fazer uma outra festa na sala. A professora comenta que sua surpresa foi causada não apenas pela resistência dos alunos, mas pela forma como questionaram, 
argumentaram e propuseram soluções, forma esta que não costumava ocorrer antes das aulas de filosofia." (Merçon, 2000, p.218) 14 [14] .

Tratemos, agora, da terceira questão que propusemos no início deste artigo - que, na verdade, constitui, aqui, a nossa motivação principal.

"Como preparar professores para fazer Filosofia com Crianças?"

Até agora, procedemos a um trabalho de resgate de nossas reflexões nas obras citadas, tentando indicar o percurso teórico prático que vimos traçando.

A terceira questão, de fato, é a que está no centro de nossas preocupações e, pela sua importância, merece que a exploremos teoricamente e que nos exercitemos em articular nossas idéias com as experiências práticas, desenvolvamos novas formas de criticar nossas próprias convicções, e elaboremos novas perguntas sobre nosso trabalho.

A formação de professores é uma questão que está na ordem do dia das reflexões no campo da educação. As formas tradicionais, que se dão em cursos de graduação ou em escolas normais vêm sendo complementadas por programas de formação à distância, ou semi-presencial, em serviço. Assim, o cotidiano do professor é o palco em que se desenvolvem as práticas e é ele que deve ser o ponto de partida e de chegada dos programas de formação.

O PFE tem desenvolvido um tipo de formação de professores que compreende cursos intensivos de iniciação à Filosofia com Crianças, palestras, cursos de extensão, grupos de estudo, seminários, reuniões semanais com os professores das escolas públicas participantes do Projeto, monitores e professores

14 [14] Merçon, Juliana. "Filosofia na Escola Classe 304 Norte,IN Filosofia na Escola Pública, Coleção Filosofia na Escola, vol. V, pp. 180-222. 
coordenadores do PFE e reuniões semanais nas escolas em que se desenvolve o trabalho, para preparação e avaliação das aulas.

Esse grupo de pessoas que faz parte do PFE constitue uma comunidade de investigação, que, seguindo os mesmos moldes metodológicos da prática do PFE nas escolas, discute o próprio Projeto, seus fundamentos filosóficos e pedagógicos, propõe procedimentos e materiais, socializa experiências e trabalha temas teóricos de seu interesse.

Tem sido uma experiência muito rica e diversificada, ano a ano, graças à mudança dos atores, professores e escolas, e ao grande número de experiências acumuladas em todos esses anos, o que tem resultado em, além do próprio Projeto, participação e organização em Congressos e Simpósios, realização de um Curso de Especialização em Ensino de Filosofia e produções teóricas, algumas delas mencionadas neste artigo.

A questão que se coloca é que como muitos dos professores não foram, eles mesmos, introduzidos à prática filosófica em sua história acadêmica, a Filosofia é uma novidade para eles. Isso não é necessariamente um entrave à prática do PFE, já que proporcionamos sua formação em serviço. Acontece que muitos deles são professores das primeiras séries e têm que dar conta de ministrar as outras disciplinas, com propósitos diferentes dos da Filosofia, cujas avaliações são formais e resultam em notas e, eventualmente, em reprovação de alunos.

Portanto, além das dificuldades comuns à formação de professores nas outras disciplinas, vemo-nos constantemente às voltas com questões específicas, como o fato de que os professores estejam, já, habituados a exercer o papel daquela pessoa que detém um determinado conhecimento e é responsável por ensiná-lo aos alunos. Por mais que as práticas fundadas no sócio-construtivismo estejam rompendo com essa concepção de educação, para a prática da filosofia como a concebemos, além da idéia de construção coletiva do conhecimento, há a dimensão não necessariamente "construtiva", mas muito mais crítica e criativa. 
Os professores que têm participado do PFE declaram vivenciar mudanças bastante radicais em sua prática cotidiana em sala de aula, não só durante o horário da aula de filosofia, mas nos das outras atividades e em sua forma de conceber a educação. Estão se transformando.

No relato de professores, podemos perceber a dimensão da mudança vivida por eles. Como na fala da Profa. Luisa: "Este projeto nos leva a refletir, repensar sobre nossa vida, nossas idéias, conceitos de 'certo', 'errado', provocando dúvidas, questionamentos sobre nós mesmos, nossa postura diante da vida, nossa prática em sala de aula e na educação como um todo. E fica... a impossibilidade de continuar a ser o que era."15 [15] (Merçon, 2000, p.180)

Mas, afinal, o que é educar?

A educação trabalha na dimensão da socialização, da formação do cidadão, e também na direção da realização do indivíduo, da formação de sua identidade.

Richard Rorty16 [16], defende que a educação básica, "é uma questão de socialização, de tentar inculcar um sentido de cidadania... objetiva promover a solidariedade enquanto requisito para a cidadania...(Rorty, 1990, p.41)

Já a educação de jovens, a educação superior, para o autor, "é mais uma questão de individualização, de tentar despertar a imaginação do indivíduo, na esperança de torná-lo capaz de auto-criação."(Rorty, idem)

Ora, como dissemos mais acima, criticamos exatamente esta educação que socializa as crianças, deixando de lado sua infância, sua capacidade de criar, que são, sim, dissolvidas, deixadas de lado, dando lugar à objetividade do adulto.

A proposta do autor, por sua vez, é de que, depois de ignorar a condição de infância, de novidade, de criatividade, em que vive a criança, e tranformar essa 15 [15] Merçon, Juliana, op. cit., pp. 180-222.

16 [16] Richard Rorty, “The Dangers of Over-Philosophication”, IN Educational Theory, 1990. p. 41. 
criança num cidadão, adulto, enquadrado, bem adaptado, a educação deve despertar nele sua imaginação.

A partir dessa proposta, perguntamos: É preciso encobrir a infância do ser humano no início da vida, para depois resgatá-la na idade adulta? Será que o objetivo da educação de crianças e o da educação de adultos devem ser diferentes?

E o que nos interessa, particularmente, aqui: $O$ papel do professor na educação de crianças é diferente daquele do professor de adultos? O primeiro estaria empenhado em socializar seu aluno e o outro em promover sua capacidade de questionar, criticar, imaginar, criar?

Talvez a única justificativa para essa atitude seja de ordem política: enquanto o indivíduo está mais criativo e crítico, enquanto ele ainda não tiver sido devidamente formatado pelos valores e regras sociais, enquanto, enfim, viver uma condição de infância primordialmente, seria uma ameaça para a sociedade educálo valorizando sua capacidade de mostrar a dimensão do novo, do inusitado. Isso poderia desestabilizar a sua própria socialização e a estrutura social. Agora, continuar a socializar o adulto de modo a impedir que ele crie, descubra o novo, seria um suicídio para a própria sociedade e civilização, na medida em que não se impulsionaria as mudanças sociais, a construção de conhecimento e a expressão artística na sociedade.

Por que a educação não poderia se propor a socializar as crianças preservando sua infância, a formação de sua identidade, convidando-as ao diálogo e à troca de experiências, de modo a que o jovem e o adulto, cidadãos engajados no estudo e no trabalho em instituições sociais, pudessem manter o prazer da descoberta, o gosto pela crítica, o encanto da criação?

Não é nisso que vimos nos empenhando no PFE? Em ajudar a formar pessoas (crianças, jovens ou adultos) não só produtivas (e talvez reprodutoras), mas criativas e envolvidas com a auto-realização? Pessoas que não só se introduzam e se adequem a seu meio social, mas que também tentem dar sentido a 
suas ações, resignificando a realidade, e que possam fazer escolhas? Este é o sentido da introdução da prática de Filosofia com Crianças. Especialmente da filosofia, tal como a definimos, que se presta muito mais a evitar do que a garantir que se socialize a criança de modo a garantir que ela se torne um adulto de tal ou qual tipo, previamente definido, aceito socialmente.

Assim, não é tão problemático que os professores não tenham tido formação filosófica. Importa que se envolvam em experiências de investigação filosófica no grupo de formação, vivenciando essa nova proposta de participação em grupos de discussão, atentando para a importância de correrem riscos, de estarem abertos para o novo, o inusitado, de terem dúvidas, estudarem, pesquisarem, de cultivarem o gosto pela busca do saber.

Nessa perspectiva, não só estamos promovendo a educação da infância, aberta à novidade e à crítica, para os professores adultos, como sugere o autor mencionado, como, e especialmente, a das crianças. Não é preciso que a criança pare de brincar, para se tornar um cidadão razoável e feliz. Talvez seja preciso, sim, que o adulto possa se envolver mais em brincadeiras, abrir-se para relações com crianças em sua alteridade, sem querer igualá-las, ou anular sua originalidade.

O ponto é: não deve haver uma forma de se educarem crianças e outra forma de se educarem adultos, ou professores. Nos grupos de formação do PFE, os professores experienciam o processo de investigação nos moldes em que vão trabalhar em sala de aula com os alunos.

Na experiência de fazer filosofia juntos, o professor questiona e reformula sua concepção de criança e a forma de se relacionar com os alunos, e estes conhecem um adulto menos engessado em suas certezas, mais aberto em suas idéias e atitudes, e vão reconstruindo sua concepção de professor.

É importante nos lembrarmos de que se não promovêssemos a educação criativa dos professores, as próprias crianças o fariam, no convívio em sala de aula, o que, aliás, elas vêem fazendo no PFE, com muito mais eficiência que nosso programa de formação dos professores. Isso se revela quando confirmamos que 
cada experiência inusitada que os professores vivem com os alunos, tem um valor incomensurável na dinâmica de sua transformação como profissionais e pessoas.

O que queremos sustentar, aqui, efetivamente, é que a formação dos professores que fazem filosofia com crianças no PFE se dá, para além do que chamamos formalmente de programa de formação, na relação deles com as crianças, nas trocas efetivas em que se envolvem, e, especialmente, num diálogo mudo, que se dá na dimensão de suas infâncias.

Este é o sentido do título deste artigo, que sugere que a prática de filosofia com crianças constitui-se em uma oportunidade de redefinição mútua de crianças e adultos.

Certamente, aqui estamos lançando um tema para reflexão. Esperamos que ele frutifique, suscite dúvidas e polêmicas e que gere muitas perguntas. 